\title{
Simulation of heat pipe-assisted latent heat thermal energy storage with simultaneous charging and discharging
}

\author{
Nourouddin Sharifi ${ }^{\text {a }}$, Amir Faghri ${ }^{\text {a, }}$, Theodore L. Bergman ${ }^{\text {b }}$, Charles E. Andraka ${ }^{c}$
}

${ }^{\mathrm{a}}$ Department of Mechanical Engineering, University of Connecticut, 191 Auditorium Road, Storrs, CT 06269-3139, USA

${ }^{\mathrm{b}}$ Department of Mechanical Engineering, University of Kansas, Lawrence, KS 66045, USA

${ }^{\mathrm{c}}$ Sandia National Laboratories, Albuquerque, NM 87185, USA

*Corresponding Author

Amir Faghri

faghri@engr.uconn.edu

Ph: +1 8604860419 


\begin{abstract}
Melting and solidification of a phase change material (PCM) held within a vertical cylindrical enclosure that is integrated with a heat pipe (HP) is simulated as a single module. The HP is heated from the bottom to melt (charge) the PCM that is positioned in the middle of the HP length, and is cooled from the top to solidify (discharge) the PCM. Three modes of operation are considered in this study $(i)$ charging-only, (ii) simultaneous charging and discharging, and (iii) discharging-only. All modes of operation are handled with a single HP within a PCM (single HP-PCM) of which the top and bottom sections are inactivated during charging-only and discharging-only modes, respectively. A parametric study of the influence of the PCM enclosure height and input/output heat transfer rates shows that, for the same mass of PCM, a longer enclosure exhibits a lower HP bottom average wall temperature and relatively more PCM melting during simultaneous charging and discharging. Increasing either the input, output, or both heat transfer rates has a significant effect on the temperature of the HP bottom and top sections, but only a minor impact on the temperature of the HP middle section.
\end{abstract}

Keywords: Heat pipe, PCM, Simultaneous charging and discharging 


\section{Nomenclature}

C

specific heat $(\mathrm{J} / \mathrm{kg} \cdot \mathrm{K})$

$c_{p} \quad$ specific heat at constant pressure $(\mathrm{J} / \mathrm{kg} \cdot \mathrm{K})$

$c_{v} \quad$ specific heat at constant volume $(\mathrm{J} / \mathrm{kg} \cdot \mathrm{K})$

D diameter (m)

$f_{\ell} \quad$ volumetric PCM liquid fraction

$g \quad$ gravitational acceleration $\left(\mathrm{m} / \mathrm{s}^{2}\right)$

$h \quad$ enthalpy $(\mathrm{J} / \mathrm{kg})$

$h_{f g} \quad$ latent heat of evaporation $(\mathrm{kJ} / \mathrm{kg})$

$h_{s \ell} \quad$ latent heat of fusion $(\mathrm{kJ} / \mathrm{kg})$

$k \quad$ thermal conductivity $(\mathrm{W} / \mathrm{m} \cdot \mathrm{K})$

$L_{a} \quad$ HP adiabatic section length (m)

$L_{B} \quad$ HP bottom section length (m)

$L_{M} \quad$ HP middle section length (m)

$L_{T} \quad$ HP top section length (m)

$p \quad$ pressure $(\mathrm{Pa})$

$q \quad$ heat transfer rate $(\mathrm{W})$

$r, z \quad$ coordinate directions (m)

$R \quad$ gas constant $(\mathrm{J} / \mathrm{kg} \cdot \mathrm{K})$

$s \quad$ source term in the temperature transforming model

$t \quad$ time $(\mathrm{s}$ or h)

T temperature $(\mathrm{K})$

$T_{m} \quad$ melting temperature (K) 
$u$

\section{Greek}

\begin{tabular}{ll}
$\beta$ & thermal expansion coefficient $\left(\mathrm{K}^{-1}\right)$ \\
$\delta T$ & half width of temperature range $(\mathrm{K})$ \\
$\Phi$ & viscous dissipation $\left(\mathrm{J} / \mathrm{kg} \cdot \mathrm{m}^{2}\right)$ \\
$\mu$ & dynamic viscosity $(\mathrm{Pa} \cdot \mathrm{s})$ \\
$v$ & kinematic viscosity $\left(\mathrm{m}^{2} / \mathrm{s}\right)$ \\
$\rho$ & density $\left(\mathrm{kg} / \mathrm{m}^{3}\right)$ \\
$S u b s c r i p t s$ & \\
$B$ & bottom \\
$e$ & enclosure \\
$e f f$ & effective \\
$h p$ & heat pipe \\
$i$ & wick-vapor interface, inner \\
$\ell$ & liquid phase of PCM \\
$o$ & outer \\
$r, z$ & coordinate directions \\
$r e f$ & reference \\
$s$ & solid phase of PCM \\
$w$ & saturation \\
\hline$a t$ & wall of the heat pipe \\
\hline &
\end{tabular}




\section{Introduction}

Concentrating solar power (CSP) plants harvest solar energy in the form of heat that can be stored in thermal energy storage devices and is ultimately used to produce electricity. The need for energy storage is due to the intermittent availability of solar irradiation and to provide a balance between the supplied loads and the demand (load leveling) during the evening hours when peak utility loads may be present.

Energy can be stored either as sensible heat or latent heat; latent storage is preferred due to its high volumetric energy density and potentially lower cost [1-5]. The temperature of the phase change material (PCM) remains nearly constant during melting (charging) and solidification (discharging) which is desirable. However, the low thermal conductivity of most PCMs limits their use in solar thermal energy generation. To alleviate this challenge, different approaches have been proposed such as dispersing high thermal conductivity particles within the PCM [6,7], using high thermal conductivity porous matrices embedded within the PCM [8,9], micro-encapsulating the PCM [10,11], and incorporating of extended surfaces and / or heat pipes (HPs) [12-19]. HPs are passive devices which utilize liquid-gas phase change to efficiently transfer heat over a long distance with a small cross-sectional area [19]. HPs can be manufactured into a variety of configurations and operational temperature ranges depending on the specific system.

When HPs are embedded in the PCM, they can increase the effective thermal conductivity of the PCM significantly. Faghri holds two patents [20, 21] for the incorporation of HPs into PCMs for latent heat thermal energy storage (LHTES) systems. The high volumetric energy density and nearly isothermal behavior of the latent storage 
is particularly advantageous to dish-Stirling systems due to the isothermal heat input requirement of Stirling engines [22].

Recent investigations have considered various aspects of integrated HP-PCM systems. Liu et al. [23] experimentally investigated a HP-heat exchanger consisting of a circumferentially-finned copper-acetone thermosyphon with stearic acid $\left(T_{m}=52.1^{\circ} \mathrm{C}\right)$ as the PCM. Heating (charging) and cooling (discharging) was induced by water flowing in two separate channels at the bottom and top of the PCM. The effects of the water inlet temperature and mass flow rate were studied. In continuation, Liu et al. [24] used the same experimental setup to investigate simultaneous charging and discharging. Heat was transferred from the hot water stream in the bottom channel through the HPs to the cold water stream in the top channel. Depending on the operational conditions, the PCM either absorbed or released thermal energy. A criterion based on a thermal resistance analysis was developed to predict whether the PCM absorbs or releases heat.

Robak et al. [25] experimentally investigated separate charging and discharging of n-octadecane housed in a cylindrical enclosure with five embedded HPs. The system was heated and cooled from below with a heat transfer fluid (HTF). The relative performance of the HPs was compared to a fin-assisted case and a non-HP, non-fin case. The results showed that the HP-assisted configuration increased melting and solidification rates compared to the non-fin, and fin-assisted cases.

A thermal network model was developed by Shabgard et al. [26] to simulate separate charging (melting) and discharging (solidification) of a LHTES system for CSP applications. Multiple HPs were installed between the HTF and PCM in two configurations; one with the PCM contained within a tube over which the HTF flowed, 
and a second with the PCM surrounding a tube that carries HTF. A heat pipe effectiveness, defined as the ratio of heat transfer in the system with HPs to that of a system without HPs, was used to quantify the improvement in heat transfer due to the HPs. In a related work, Shabgard et al. [27] performed a heat transfer and exergy analysis of a large scale, cascaded LHTES system using thermosyphons for CSP. The transient response of the LHTES during either charging and discharging was predicted. The optimum arrangement of HPs in two HP-assisted LHTES configurations was identified by Nithyanandam and Pitchumani [28]. The configurations were (i) a PCM housed inside tubes exposed to a cross flow of HTF, and (ii) a PCM surrounding the HTF tubes.

The two-dimensional transient response of a conjugate HP-PCM system including the effects of natural convection was numerically simulated by Sharifi et al. [29]. A vertically-oriented HP was concentrically embedded in a PCM held in a cylindrical enclosure. The melting process of the HP-PCM arrangement was compared with melting induced by an isothermal surface, a solid rod, and a hollow tube, all of the same height and outer diameter as the HP. It was shown that the HP significantly enhanced the melting rate compared to that of rods or tubes. It was found that the effectiveness, defined as the volumetric liquid fraction of the HP-PCM relative to the volumetric liquid fraction of the Rod-PCM, of the HP-PCM was doubled compared to the Rod-PCM. It was also shown that the HP-PCM is particularly effective, compared to the Rod-PCM, in increasing the melting rate in a system heated from above.

Recently, it has been suggested that the application of LHTES to dish-Stirling CSP systems may be desirable due to the match between the near isothermal input requirements of Stirling engines and the near isothermal nature of phase change processes 
[22]. Specifically, Sandia National Laboratories has proposed a LHTES design for dishStirling systems that involves multiple dual HP-PCM modules. A dual HP-PCM module is comprised of two HPs, one of which is associated with charging the PCM (encompassing only the hot source and PCM) and the other with discharging the PCM (only the PCM and cold source). The full-scale system, as proposed in [22], consists of multiple dual HP-PCM modules which contain two distinct sets of HPs, where one set is for charging the PCM and the other for discharging the PCM. This configuration leads to a complicated three-dimensional behavior involving distinct as well as simultaneous charging and discharging. A simplified two-dimensional configuration was analyzed by Shabgard et al. [30] to approximate the three-dimensional configuration of [22], based on a physically-reasonable geometric argument. The investigators studied three modes of operation for a typical daily cycle: (i) charging-only, (ii) simultaneous charging and discharging, and (iii) discharging-only. Systems with various geometrical configurations were investigated.

Few HP-PCM studies account for simultaneous charging and discharging, a situation relevant to the Sandia dish-Stirling engine concept. Therefore the objective of this study is to simulate the melting and solidification processes of a PCM induced by a HTF to a single HP for three different modes of operations: Mode I (charging-only), Mode II (concurrent charging and discharging) and Mode III (discharging-only). This work considers an alternative configuration relative to the configuration presented in [30] which may be a more economical and simpler design.

\section{Physical model and formulations}


In this study HP is concentrically positioned in a vertical cylindrical enclosure filled with PCM. The PCM enclosure is situated about the middle section of the HP. The bottom and top sections of the HP are exposed to a specified power or temperature for the different modes of operation. As will become evident, a parametric study is performed to determine the influence of the PCM enclosure height and input/output power.

Figure 1 shows the computational domain for the vertically-oriented HP-PCM system. The HP is subdivided into three radial regions: (i) the working fluid vapor, (ii) the porous wick (that is assumed to be saturated with the liquid working fluid), and (iii) the solid wall. The PCM is contained in the cylindrical annulus of length $L_{M}$, which surrounds the middle section of the HP. The adiabatic transport sections of the HP are each of length $L_{a}$. The HP's bottom and top sections are of length $L_{B}$ and $L_{T}$, respectively.

Three fundamental modes of operation are considered in the modeling enumerated as: Mode I, in which the HP is heated at its bottom section while the HP top section is adiabatic, Mode II, in which the bottom (top) section of the HP is heated (cooled), and Mode III, in which the bottom section of the HP is adiabatic and the top section of the HP is cooled. Mode I involves charging (melting) -only, Mode II is characterized by simultaneous charging and discharging, while Mode III involves discharging (solidifying) -only. It is noted that the middle section of the HP operates as a condenser in Mode I, a condenser and/or evaporator during Mode II, and an evaporator in Mode III.

Several assumptions are made. All properties are constant except the vapor density of the HP working fluid. The PCM enclosure walls, as well as the top and bottom end caps of the HP, are adiabatic. However, a more practical scenario accounting for heat loss to the ambient is also considered by specifying convection heat losses at the PCM 
enclosure walls. The pure molten PCM is of the same density as the solid, and the melt is a Boussinesq fluid. Natural convection in the molten PCM is two-dimensional, and laminar. All materials are opaque to thermal radiation, and thermal radiation within the HP is neglected. The vapor phase of the HP working fluid is an ideal gas experiencing two-dimensional laminar compressible flow, and the HP wick is fully saturated with liquid. The HP working fluid at the wick-vapor interface is saturated, and the liquid flow in the wick is neglected [31]. The wick is assumed to be capable of providing adequate capillary pressure to drive the liquid flow through the wick for the operating conditions and different modes presented here.

As is evident, numerous physical boundaries separate the various materials, phases, and components within the conjugate system. Thermal contact resistances are neglected and the system is described with a single computational domain. The computational domain of Fig. 1 is therefore subject to the following boundary and initial conditions. Radial gradients of temperature $T$, pressure $p$, and velocity component $u_{z}$, in addition to the velocity component $u_{r}$, are zero at $r=0$. The heat input (output) to the HP is uniformly applied. Hence, during Mode I $q_{B}$ is positive while $q_{T}$ is zero, during Mode II $q_{B}$ is positive while $q_{T}$ is negative, and during Mode III $q_{B}$ is zero while $q_{T}$ is negative.

The remaining external boundaries are adiabatic and impermeable, and no-slip conditions are specified. The entire domain is initially at the melting temperature of the PCM, which is initially solid.

\subsection{Phase change material}

The thermal response of the PCM is described by the following continuity, momentum and energy equations $[32,33]$ : 


$$
\begin{gathered}
\frac{\partial u_{r}}{\partial r}+\frac{u_{r}}{r}+\frac{\partial u_{z}}{\partial z}=0 \\
\frac{\partial u_{r}}{\partial t}+u_{r} \frac{\partial u_{r}}{\partial r}+u_{z} \frac{\partial u_{r}}{\partial z}=-\frac{1}{\rho} \frac{\partial p}{\partial r}+v\left(\frac{\partial^{2} u_{r}}{\partial r^{2}}+\frac{1}{r} \frac{\partial u_{r}}{\partial r}-\frac{u_{r}}{r^{2}}+\frac{\partial^{2} u_{r}}{\partial z^{2}}\right) \\
\frac{\partial u_{z}}{\partial t}+u_{r} \frac{\partial u_{z}}{\partial r}+u_{z} \frac{\partial u_{z}}{\partial z}=-\frac{1}{\rho} \frac{\partial p}{\partial z}+v\left(\frac{\partial^{2} u_{z}}{\partial r^{2}}+\frac{1}{r} \frac{\partial u_{z}}{\partial r}+\frac{\partial^{2} u_{z}}{\partial z^{2}}\right)+g\left[\beta\left(T-T_{m}\right)-1\right] \\
\frac{\partial h}{\partial t}+u_{r} \frac{\partial h}{\partial r}+u_{z} \frac{\partial h}{\partial z}=\frac{1}{\rho}\left[\frac{1}{r} \frac{\partial}{\partial r}\left(k r \frac{\partial T}{\partial r}\right)+\frac{\partial}{\partial z}\left(k \frac{\partial T}{\partial z}\right)\right]
\end{gathered}
$$

One may define a scaled temperature as $T^{*}=T-T_{m}$ and express the enthalpy by the temperature transforming model [34], resulting in:

$$
h=c\left(T^{*}+s\right)
$$

where

$$
\begin{aligned}
& c= \begin{cases}c_{s} & T^{*}<-\delta T \\
\frac{c_{s}+c_{\ell}}{2}+\frac{h_{s \ell}}{2 \delta T} & -\delta T \leq T^{*} \leq \delta T \\
c_{\ell} & T^{*}>\delta T\end{cases} \\
& s= \begin{cases}\delta T & T^{*}<-\delta T \\
\delta T & -\delta T \leq T^{*} \leq \delta T \\
\frac{c_{s}}{c_{\ell}} \delta T+\frac{h_{s \ell}}{c_{\ell}} & T^{*}>\delta T\end{cases}
\end{aligned}
$$

Hence, the energy equation can be written as:

$$
\begin{aligned}
\frac{\partial\left(\rho c T^{*}\right)}{\partial t}+u_{r} \frac{\partial\left(\rho c T^{*}\right)}{\partial r}+ & u_{z} \frac{\partial\left(\rho c T^{*}\right)}{\partial z}= \\
& \frac{1}{r} \frac{\partial}{\partial r}\left(k r \frac{\partial T^{*}}{\partial r}\right)+\frac{\partial}{\partial z}\left(k \frac{\partial T^{*}}{\partial z}\right)-\frac{\partial(\rho c s)}{\partial t}-u_{r} \frac{\partial(\rho c s)}{\partial r}-u_{z} \frac{\partial(\rho c s)}{\partial z}
\end{aligned}
$$


where

$$
k= \begin{cases}k_{s} & T^{*}<-\delta T \\ k_{s}+\left(k_{\ell}-k_{s}\right) \frac{T^{*}+\delta T}{2 \delta T} & -\delta T \leq T^{*} \leq \delta T \\ k_{\ell} & T^{*}>\delta T\end{cases}
$$

\subsection{Heat pipe}

Based on the preceding assumptions, the vapor flow in the HP is described by the continuity equation [19]:

$$
\frac{\partial \rho}{\partial t}+\frac{1}{r} \frac{\partial}{\partial r}\left(\rho r u_{r}\right)+\frac{\partial}{\partial z}\left(\rho u_{z}\right)=0
$$

and the $r$ - and $z$ - momentum equations:

$$
\begin{aligned}
\frac{\partial}{\partial t}\left(\rho u_{r}\right)+\frac{1}{r} \frac{\partial}{\partial r}\left(\rho r u_{r}^{2}\right)+\frac{\partial}{\partial z}\left(\rho u_{r} u_{z}\right)= & -\frac{\partial p}{\partial r}+\frac{1}{r} \frac{\partial}{\partial r}\left(\mu r \frac{\partial u_{r}}{\partial r}\right)+\frac{\partial}{\partial z}\left(\mu \frac{\partial u_{r}}{\partial z}\right)-\frac{\mu u_{r}}{r^{2}}+\frac{1}{3} \mu \frac{\partial}{\partial r}\left(\frac{1}{r} \frac{\partial}{\partial r}\left(r u_{r}\right)+\frac{\partial u_{z}}{\partial z}\right) \\
& +\frac{\partial \mu}{\partial r}\left(\frac{\partial u_{r}}{\partial r}-\frac{2}{3}\left(\frac{1}{r} \frac{\partial}{\partial r}\left(r u_{r}\right)+\frac{\partial u_{z}}{\partial z}\right)\right)+\frac{\partial \mu}{\partial z} \frac{\partial u_{z}}{\partial z} \\
\frac{\partial}{\partial t}\left(\rho u_{z}\right)+\frac{1}{r} \frac{\partial}{\partial r}\left(\rho r u_{r} u_{z}\right)+\frac{\partial}{\partial z}\left(\rho u_{z}^{2}\right)= & -\rho g-\frac{\partial p}{\partial z}+\frac{1}{r} \frac{\partial}{\partial r}\left(\mu r \frac{\partial u_{z}}{\partial r}\right)+\frac{\partial}{\partial z}\left(\mu \frac{\partial u_{z}}{\partial z}\right)+\frac{1}{3} \mu \frac{\partial}{\partial z}\left(\frac{1}{r} \frac{\partial}{\partial r}\left(r u_{r}\right)+\frac{\partial u_{z}}{\partial z}\right) \\
& +\frac{\partial \mu}{\partial z}\left(\frac{\partial u_{z}}{\partial z}-\frac{2}{3}\left(\frac{1}{r} \frac{\partial}{\partial r}\left(r u_{r}\right)+\frac{\partial u_{z}}{\partial z}\right)\right)+\frac{\partial \mu}{\partial r} \frac{\partial u_{r}}{\partial z}
\end{aligned}
$$

The energy equation for the vapor phase of the HP working fluid is:

$$
\frac{\partial}{\partial t}(\rho h)+\frac{1}{r} \frac{\partial}{\partial r}\left(\rho r u_{r} h\right)+\frac{\partial}{\partial z}\left(\rho u_{z} h\right)=\frac{D p}{D t}+\frac{1}{r} \frac{\partial}{\partial r}\left(k r \frac{\partial T}{\partial r}\right)+\frac{\partial}{\partial z}\left(k \frac{\partial T}{\partial z}\right)+\mu \Phi
$$

where the viscous dissipation term is:

$$
\Phi=2\left[\left(\frac{\partial u_{r}}{\partial r}\right)^{2}+\left(\frac{u_{r}}{r}\right)^{2}+\left(\frac{\partial u_{z}}{\partial z}\right)^{2}\right]+\left(\frac{\partial u_{r}}{\partial z}+\frac{\partial u_{z}}{\partial r}\right)^{2}-\frac{2}{3}\left[\frac{1}{r} \frac{\partial}{\partial r}\left(r u_{r}\right)+\frac{\partial u_{z}}{\partial z}\right]^{2}
$$

Using the ideal gas equation of state and the enthalpy-internal energy relation, the energy equation can be rewritten as: 


$$
\frac{\partial}{\partial t}\left(\rho c_{v} T\right)+\frac{1}{r} \frac{\partial}{\partial r}\left(\rho r u_{r} c_{v} T\right)+\frac{\partial}{\partial z}\left(\rho u_{z} c_{v} T\right)=\frac{1}{r} \frac{\partial}{\partial r}\left(k r \frac{\partial T}{\partial r}\right)+\frac{\partial}{\partial z}\left(k \frac{\partial T}{\partial z}\right)-p\left(\frac{1}{r} \frac{\partial}{\partial r}\left(r u_{r}\right)+\frac{\partial u_{z}}{\partial z}\right)+\mu \Phi
$$

It is assumed that the HP wick is saturated with liquid of negligible velocity, as modeled by Cao and Faghri [31]. Therefore, the heat conduction equation for the wick is:

$$
\left(\rho c_{p}\right)_{e f f} \frac{\partial T}{\partial t}=k_{e f f}\left[\frac{1}{r} \frac{\partial}{\partial r}\left(r \frac{\partial T}{\partial r}\right)+\frac{\partial^{2} T}{\partial z^{2}}\right]
$$

The temperature distribution in the solid wall of the HP is governed by:

$$
\left(\rho c_{p}\right)_{w} \frac{\partial T}{\partial t}=k_{w}\left[\frac{1}{r} \frac{\partial}{\partial r}\left(r \frac{\partial T}{\partial r}\right)+\frac{\partial^{2} T}{\partial z^{2}}\right]
$$

The same approach as [29] is used to enforce the saturation condition at the vaporwick interface for the HP, i.e., the saturation pressure is specified corresponding to the interfacial vapor temperature via the Clausius-Clapeyron equation as described below:

$$
P_{v, i}=P_{s a t}\left(T_{v, i}\right)=P_{r e f} \exp \left[\frac{h_{f g}}{R}\left(\frac{1}{T_{r e f}}-\frac{1}{T_{v, i}}\right)\right]
$$

The interfacial velocity is determined by the mass balance of the vapor control volumes adjacent to the interface where the pressure is specified. Also, the latent heats (interfacial mass flow rate times the HP working fluid latent heat of vaporization) corresponding to the interfacial velocities are applied as source terms in the energy equations for the vapor control volumes adjacent to the interface.

\section{Numerical procedure}

The numerical methodology used here is described in detail elsewhere $[29,35]$ and is summarized as follows. The finite volume approach is used to discretize the governing 
equations and the central differencing scheme is applied to the advection and diffusion terms [36]. For the time discretization, a fully-implicit scheme, employing a standard underrelaxation version of the consistent update technique [37] or SUV-CUT is used. An explicit update scheme is utilized to evaluate the buoyancy source term in the momentum equation. A pressure-decoupled solid velocity correction is used to ensure zero velocity in the solid PCM, HP wall and wick. The algebraic equations are solved using a multigrid solver [38] with the SIP [39] smoother. Preliminary simulations were performed using grid sizes up to $120 \times 120(z \times r)$. A $100 \times 100$ grid with a time step of $t=0.1$ s was found to be sufficient to achieve grid size and time step independent solutions. A convergence criterion (maximum difference between two successive iterations and matrix residuals) of $10^{-5}$ was specified for all independent variables.

\section{Results and discussion}

The heat pipe considered in this study has a diameter of $D_{h p}=2 r_{h p}=8 \mathrm{~mm}$ with wall and wick thicknesses of $1 \mathrm{~mm}$ each. The wick is a felt metal with a porosity of $\omega=0.9$. There are two adiabatic transport sections as shown in Fig. 1, each of length $L_{a}=5 \mathrm{~mm}$. The HP bottom and top sections are $L_{B}=L_{T}=25 \mathrm{~mm}$. The HP middle section (or PCM enclosure length) is specified to be $L_{M}=20 \mathrm{~mm}, 30 \mathrm{~mm}$ or $40 \mathrm{~mm}$, therefore the overall HP length changes accordingly. The PCM enclosure inner radius is equal to the HP outer radius $\left(r_{i}=r_{h p}\right)$ and to consider a fixed volume of PCM, the enclosure outer radius is $r_{e, o}$ $=25 \mathrm{~mm}, 20.5 \mathrm{~mm}$ and $18 \mathrm{~mm}$ for $L_{M}=20 \mathrm{~mm}, 30 \mathrm{~mm}$ and $40 \mathrm{~mm}$, respectively. The HP working fluid is sodium and the PCM is a metal $(\mathrm{Cu}-0.3 \mathrm{Si}$, wt.\%). It is noted that stainless steel, which was used as the HP wall and wick, is chemically compatible with 
the HP working fluid [19] and is also assumed to be compatible with the PCM used in this work. Relevant thermophysical properties are provided in Table 1.

Heat transfer behavior: As noted previously, each simulation begins with the PCM in the solid phase and all temperatures at $T_{m}=1076 \mathrm{~K}$. To illustrate the heat transfer behavior of the system, the external vertical surface of the HP in the bottom section is exposed to a constant and uniform heat transfer rate of $q_{B}$, while in the top section is exposed to either constant and uniform heat transfer rate $\left(q_{T}=-q_{B}\right)$ or constant and uniform temperature $T_{T}=1071 \mathrm{~K}\left(T_{T}=T_{M}-5 \mathrm{~K}\right)$. Depending on the operation scheme of the Stirling engine, a constant power output or a constant temperature at the hot interface (HP top section) may be desired. To predict the behavior of the system for each of these operation scenarios, both boundary conditions are considered. Three powers of $q_{B}=10 \mathrm{~W}$, $15 \mathrm{~W}$ and $20 \mathrm{~W}$ are considered. As mentioned in section 2, three modes of operation are considered here. Mode I $\left(q_{B}>0, q_{T}=0\right)$ starts at $t=0$ and ends when the PCM liquid fraction reaches $f_{\ell}=0.5$, at which time Mode II $\left(q_{B}>0, q_{T}<0\right)$ begins. The duration of Mode II is specified to be $1 \mathrm{~h}$. Mode III $\left(q_{B}=0, q_{T}<0\right)$ starts at the conclusion of Mode II and ends when the PCM is completely solid.

Figure 2 shows the isotherms for different modes of operation and values of $L_{M}$. The HP top section boundary condition is $q_{T}=-q_{B}$ during both Mode II and Mode III. Isotherms are shown at intervals of $0.02 \mathrm{~K}(1 \mathrm{~K})$ over the range $1076 \mathrm{~K} \leq T \leq 1076.3 \mathrm{~K}$ (1076.5 K $\leq T \leq 1094.5 \mathrm{~K}$ ) for Mode $\mathrm{I}$, and at intervals of $1 \mathrm{~K}, 0.1 \mathrm{~K}, 0.02 \mathrm{~K}$ and $1 \mathrm{~K}$ over the range of $1055 \mathrm{~K} \leq T \leq 1075 \mathrm{~K}, 1075 \mathrm{~K} \leq T \leq 1076 \mathrm{~K}, 1076 \mathrm{~K} \leq T \leq 1076.3 \mathrm{~K}$ and 1076.5 $\mathrm{K} \leq T \leq 1094.5 \mathrm{~K}$, respectively for Mode II. Isotherms are shown at intervals of $1 \mathrm{~K}(0.1 \mathrm{~K})$ over the range $1055 \mathrm{~K} \leq T \leq 1075 \mathrm{~K}(1075 \mathrm{~K} \leq T \leq 1076 \mathrm{~K})$ for Mode III. 
The isotherms are presented at times corresponding to $f_{\ell}=0.5(0.4)$ for Mode II (Mode I and Mode III).

Temperature distributions within the HP in Mode I (Mode III) show that the top (bottom) section of the HP is deactivated while the entire length of the HP is active in Mode II. The temperature distributions of the HP working fluid are influenced by the vapor velocity which can be as high as $\approx 100 \mathrm{~m} / \mathrm{s}$. No sonic limitations were found for the HP considered in this study.

During Mode I a weak clockwise natural convection circulation develops in the melt as it expands. There is a secondary counter-clockwise circulation of the molten PCM adjacent to the HP wall during Mode II. In any case, the temperature distribution in the PCM is only weakly affected by natural convection due to the high thermal conductivity of the PCM. The melting rate is nearly constant (the HP mass varies as $L_{M}$ changes since the HP overall length changes) for different $L_{M}$ values since the input/output powers and the PCM mass are the same for all configurations. Figure 3 includes predicted melting with and without natural convection occurred for a typical case. As can be seen, the PCM liquid fraction is not influenced significantly by natural convection.

The time evolution of the solid - liquid interfaces is shown in Fig. 4. During Mode I, there is only one solid region while at early times during Mode II, a second solid region develops in the top left of the PCM adjacent to the HP. As time passes, these two solid regions merge with liquid remaining in the middle and bottom portions of the enclosure. As Mode III progresses, the solid-liquid interface advances from the HP outward.

Typical axial distributions of the exterior temperature of the HP are reported in Fig. 5 for $L_{M}=30 \mathrm{~mm}$ and $q_{B}=15 \mathrm{~W}$. For $q_{T}=0$ or $-15 \mathrm{~W}$, conditions are shown in Fig. $5 \mathrm{a}$ at 
the end of Mode I $(t=3870 \mathrm{~s})$, at the end of Mode II $(t=7470 \mathrm{~s})$, and at an intermediate time during Mode III when $f_{\ell}=0.4$. At the conclusion of the charging process $(t=3870$ $\mathrm{s})$, the maximum temperature exists at $z=0 \mathrm{~m}$, as expected. The temperature adjacent to the PCM is near the PCM melting temperature because of the high thermal conductivity of the phase change material, while the temperature distribution along the non-active (top) section of the HP exhibits slight undulations, reflecting modest localized (and offsetting) condensation and evaporation within the HP. The entire HP length is active during simultaneous charging and discharging (Mode II); with minimum (maximum) HP wall temperatures existing at the top (bottom) of the HP, as expected. During discharge (Mode III), the temperature undulations switch positions to the bottom section of the HP, again reflecting the modest local condensation and evaporation within the HP. Predictions associated with $T_{T}=1071 \mathrm{~K}$ ( or $q_{T}=0$ ) are presented in Fig. 5b. Similar axial HP temperatures were noted for all the cases considered here.

Figure 6 shows the PCM liquid fraction histories for different input powers with constant $L_{M}=30 \mathrm{~mm}$. The HP top section is exposed to $q_{T}\left(q_{T}=-q_{B}\right.$; Fig. 6a) and $T_{T}=$ $1071 \mathrm{~K}$ (Fig. 6b). In Mode I, the liquid fraction linearly increases until $f_{\ell}=0.5$. The time period for Mode II is specified as $1 \mathrm{~h}$ as previously mentioned. The total operation time (summation of time duration of each mode) increases as input power decreases. However, this effect is more profound for the case when the HP top boundary condition is $q_{T}\left(q_{T}=-\right.$ $q_{B}$ ) rather than $T_{T}=1071 \mathrm{~K}$. It is clear that in Fig. $6 \mathrm{~b}$, the melting process is slightly more dominant than the solidification process during Mode II since the liquid fraction increases with time for $q_{B}=15 \mathrm{~W}$ and $20 \mathrm{~W}$. However, for $q_{B}=10 \mathrm{~W}$, the melting rate is approximately equal to the solidification rate as seen by the nearly constant liquid 
fraction throughout Mode II. In reality, providing perfectly adiabatic conditions for the HP bottom section ( $L_{B}$, evaporator for Mode I) during Mode III may not be practical and some heat loss from the HP bottom section may exist. To study this effect during Mode III, a case with $T_{B}=1075 \mathrm{~K}$ ( $1 \mathrm{~K}$ less than the PCM melting point) was considered. This corresponds to a heat loss of approximately $1 \mathrm{~W}$ from the HP bottom section. The result in terms of liquid fraction is presented in Fig. $6 \mathrm{~b}$ with the dash-dot-dot line. The liquid fraction trend is similar to the case $q_{B}=0$ during Mode III except the total operation time (or the time corresponding to Mode III) is reduced by approximately $3 \%$ compared to the case $q_{B}=0$.

The influence of $L_{M}$ and $q_{B}$ on the HP output power is shown in Fig. 7. For each case, the temperature of $T_{T}$ is applied to the outer wall of the HP top section during Mode II and III. The output power, $q_{T}$, decreases (increases) as the input power, $q_{B}$, decreases during Mode II (Mode III) for each $L_{M}$. The output power decreases as $L_{M}$ increases. During Mode II, as $L_{M}$ increases, relatively more heat is transferred to the PCM rather than directly to the top section since the heat transfer area between the HP and the PCM increases. This leads to a reduction in the HP middle section average wall temperature which results in a lower output heat transfer rate during Mode III. Overall, the duration of each $q_{T}$ is larger for higher $q_{B}$.

Time-varying heat input: Rather than a constant input heat transfer rate, a variable input heat transfer rate may also play an important role from a practical point of view, especially in solar applications. The input solar heat transfer rate is calculated based upon hourly direct normal irradiance (DNI) data provided by NREL (National Renewable Energy Laboratory). To calculate the instantaneous input heat transfer rate to the PCM in 
an LHTES system, DNI data for Albuquerque, New Mexico during the month of June 2010 was employed [30]. A dish diameter of $11 \mathrm{~m}$ and a combined dish optical efficiency and receiver efficiency of 0.93 were specified for the full-scale system. The resulting hourly DNI values are shown in Fig. 8a. Since the present analysis is limited to the laminar natural convection regime within the melt, the PCM enclosure was scaled down to prevent the establishment of turbulent flow. This practice also helps to reduce the number of computational cells in the simulations and consequently CPU time. The input heat transfer rate for the scaled down system was determined by multiplying the input heat transfer rate of the full-scale system by a scaling factor based on PCM volume. The instantaneous input heat transfer rate for the small-scale system is shown in Fig. $8 \mathrm{~b}$ as $q_{B 1}$. A second order polynomial $\left(\approx-0.043 \times t^{2}+0.72 \times t\right)$ is curve fit to the actual data for $q_{B 1}$ in order to utilize a more computationally simple input heat transfer data for use in the modeling.

In the simulation to follow, the heat loss from the PCM enclosure to the environment is also considered. A convective boundary condition is applied to the PCM enclosure (bottom, top, and lateral surfaces). The ambient temperature is specified to be $300 \mathrm{~K}$ and an overall heat transfer coefficient of $0.8 \mathrm{~W} / \mathrm{m}^{2} \cdot \mathrm{K}$ is assumed to account for both external convection and insulation. The HP top thermal boundary condition was assumed to be $T_{T}=1074 \mathrm{~K}$, in which the output heat transfer rate is approximately $70 \%$ of the input heat transfer rate [22]. The corresponding PCM liquid fraction is presented in Fig. 9 for all three modes. Mode I begins at $t=0 \mathrm{~h}$ until $f_{\ell}=0.5$. Mode II occurs from $f_{\ell}=$ 0.5 until $q_{B I}=0 \mathrm{~W}$. Mode III $\left(q_{B I}=0, q_{T}<0\right)$ starts at the conclusion of Mode II and ends when the PCM is completely solid. During Mode III, Fig. 9 shows that the PCM 
storage serves approximately $7 \mathrm{~h}$ of energy delivery in the absence of an input heat transfer rate. Therefore, when the system PCM volume is increased to the full-scale value, the time duration for energy delivery is expected to be approximately $7 \mathrm{~h}$. This time duration is an acceptable value for a typical solar LHTES system [22].

\section{Conclusions}

A numerical model has been developed to simulate conjugate heat transfer involving a vertically-oriented single HP integrated with a PCM. Three modes of operation including (i) charging-only, (ii) simultaneous charging and discharging and (iii) discharging-only were considered.

Melting and solidification rates are governed by conjugate heat transfer effects including conduction in the HP wick and wall, vaporization and condensation of the compressible HP working fluid, and conduction (natural convection) in the solid (molten) PCM which has an evolving topography. Parametric studies show that for the same mass of PCM, a larger enclosure aspect ratio (height to diameter of the PCM enclosure) exhibits a lower average HP bottom wall temperature and promotes more melting during simultaneous charging and discharging due to a combination of a greater heat transfer area and less conduction distance in the PCM for the smaller diameter of the PCM.

The single HP-PCM module configuration can be utilized for LHTES systems involving either sequential or simultaneous melting and solidification. Single set HPPCM systems (consisting of multiple single HP-PCM modules) can potentially be more economical and simpler in design compared to alternative configurations such as dual set HP-PCM systems [30]. In order for the system to economically achieve its highest 
performance, the ratio of the volume occupied by the HPs within the PCM to the total volume of the storage system (PCM as well as HP volume) must be optimized in future work.

\section{Acknowledgement}

Sandia National Laboratories sponsored this project. Sandia National Laboratories is a multi-program laboratory managed and operated by Sandia Corporation, a wholly owned subsidiary of Lockheed Martin Corporation, for the U.S. Department of Energy's National Nuclear Security Administration under contract DE-AC04-94AL85000.

\section{References:}

[1] B. Zalba, J.M. Marin, L.F. Cabeza, H. Mehling, Review on thermal energy storage with phase change: materials, heat transfer analysis and applications, Applied Thermal Engineering 23 (3) (2003) 251-283.

[2] M.M. Farid, A.M. Khudhair, S.A.K. Razack, S. Al-Hallaj, A review on phase change energy storage: materials and applications, Energy Conversion Management 45 (9-10) (2004) 1597-1615.

[3] S.D. Sharma, K. Sagara, Latent heat storage materials and systems: a review, International Journal of Green Energy 2 (1) (2005) 1-56.

[4] F. Agyenim, N. Hewitt, P. Eames, M. Smyth, A review of materials, heat transfer and phase change problem formulation for latent heat thermal energy storage systems (LHTESS), Renewable and Sustainable Energy Reviews 14 (2) (2010) $615-628$. 
[5] C.W. Lan, D.T. Yang, Dynamic simulation of the vertical zone-melting crystal growth, International Journal of Heat and Mass Transfer 41 (24) (1998) 43514373.

[6] S. Jegadheeswaran, S.D. Pohekar, Energy and exergy analysis of particle dispersed latent heat storage system, International Journal of Energy and Environment 1 (3) (2010) 445- 458.

[7] H. Ettouney, I. Alatiqi, M. Al-Sahali, K. Al-Hajirie, Heat transfer enhancement in energy storage in spherical capsules filled with paraffin wax and beads, Energy Conversion and Management 47 (2006) 211-228.

[8] O. Mesalhy, K. Lafdi, A. Elgafy, K. Bowman, Numerical study for enhancing the thermal conductivity of phase change material (PCM) storage using high thermal conductivity porous matrix, Energy Conversion and Management 46 (6) (2005) $847-867$.

[9] J.M. Martin, B. Zalba, L.F. Cabeza, H. Mehling, Improvement of a thermal energy storage using plates with paraffin-graphite composite, International Journal of Heat and Mass Transfer 48 (12) (2005) 2561-2570.

[10] A. Sari, C. Alkan, A. Karaipekli, O. Uzun, Microencapsulated n-octacosane as phase change material for thermal energy storage, Solar Energy 83 (10) (2009) $1757-1763$.

[11] M.N.A. Hawlader, M.S. Uddin, M.M. Khin, Microencapsulated PCM thermal energy storage system, Applied Energy 74 (2003) 195-202. 
[12] M. Lacroix, M. Benmadda, Numerical simulation of natural convectiondominated melting and solidification from a finned vertical wall, Numerical Heat Transfer Part A-Application 31 (1) (1997) 71-86.

[13] M. Lacroix, M. Benmadda, Analysis of natural convection melting from a heated wall with vertically oriented fins, International Journal of Numerical Methods for Heat and Fluid Flow 8 (4) (1998) 465-478.

[14] M.J. Huang, P.C. Eames, B. Norton, Thermal regulation of building-integrated photovoltaics using phase change materials, International Journal of Heat and Mass Transfer 47 (12-13) (2004) 2715-2733.

[15] V. Shatikian, G. Ziskind, R. Letan, Numerical investigation of a PCM-based heat sink with internal fins, International Journal of Heat and Mass Transfer 51 (5-6) (2008) 1488-1493.

[16] R. Akhilesh, A. Narasimhan, C. Balaji, Method to improve geometry for heat transfer enhancement in PCM composite heat sinks, International Journal of Heat and Mass Transfer 48 (13) (2005) 2759-2770.

[17] M. Gharebaghi, I. Sezai, Enhancement of heat transfer in latent heat storage modules with internal fins, Numerical Heat Transfer Part A - Application 53 (7) (2008) 749-765.

[18] N. Sharifi, T.L. Bergman, A. Faghri, Enhancement of PCM melting in enclosures with horizontally-finned internal surfaces, International Journal of Heat and Mass Transfer 54 (19-20) (2011) 4182-4192.

[19] A. Faghri, Heat Pipe Science and Technology, Taylor \& Francis, Washington, D.C., 1995. 
[20] A. Faghri, Thermal Energy Storage Heat Exchanger, US Patent No. 4976308, 1990.

[21] A. Faghri, Micro Heat Pipe Energy Storage System, US Patent No. 5000252, 1991.

[22] C.E. Andraka, K.S. Rawlinson, N.P. Siegel, Technical feasibility of storage on large dish Stirling systems, Sandia report SAND2012-8352 (2012).

[23] Z. Liu, Z. Wang, C. Ma, An experimental study on heat transfer characteristics of heat pipe heat exchanger with latent heat storage. Part I: charging only and discharging only modes, Energy Conversion and Management 47 (2006) 944966.

[24] Z. Liu, Z. Wang, C. Ma, An experimental study on heat transfer characteristics of heat pipe heat exchanger with latent heat storage, Part II: Simultaneous charging/ discharging modes, Energy Conversion and Management 47 (7-8) (2006) 967-991. [25] C.W. Robak, T.L. Bergman, A. Faghri, Enhancement of latent heat energy storage using embedded heat pipes, International Journal of Heat and Mass Transfer $54(15-16)(2011) 3476-3484$.

[26] H. Shabgard, T.L. Bergman, N. Sharifi, A. Faghri, High temperature latent heat thermal energy storage using heat pipes, International Journal of Heat and Mass Transfer 53 (15-16) (2010) 2979-2988.

[27] H. Shabgard, C.W. Robak, T.L. Bergman, A. Faghri, Heat transfer and exergy analysis of cascaded latent heat storage with gravity-assisted heat pipes for concentrating solar power applications, Solar Energy 86 (3) (2012) 816-830. 
[28] K. Nithyanandam, R. Pitchumani, Analysis and optimization of a latent thermal energy storage system with embedded heat pipes, International Journal of Heat and Mass Transfer 54 (21-22) (2011) 4596-4610.

[29] N. Sharifi, S. Wang, T.L. Bergman, A. Faghri, Heat pipe-assisted melting of a phase change material, International Journal of Heat and Mass Transfer 55 (1314) (2012) $3458-3469$.

[30] H. Shabgard, A. Faghri, T.L. Bergman, C.E. Andraka, Numerical simulation of heat pipe-assisted latent heat thermal energy storage unit for dish-Stirling systems, Journal of Solar Energy Engineering 136 (2) (2014) 021025-1-12.

[31] Y. Cao, A. Faghri, Transient two-dimensional compressible analysis for hightemperature heat pipes with pulsed heat input, Numerical Heat Transfer Part A Applications 18 (4) (1990a) 483-502.

[32] A. Faghri, Y. Zhang, Transport Phenomena in Multiphase Systems, Academic Press, Elsevier, New York, 2006.

[33] A. Faghri, Y. Zhang, J. Howell, Advanced Heat and Mass Transfer, Global Digital Press, Columbia, Missouri, 2010.

[34] Y. Cao, A. Faghri, A numerical analysis of phase change problem including natural convection, ASME Journal of Heat Transfer 112 (1990b) 812-815.

[35] S. Wang, A. Faghri, T.L. Bergman, A comprehensive numerical model for melting with natural convection, International Journal of Heat and Mass Transfer 53 (9-10) (2010a) 1986-2000.

[36] S.V. Patankar, Numerical Heat Transfer and Fluid Flow, McGraw-Hill, New York, 1980. 
[37] W.W. Jin, W.Q. Tao, Y.L. He , Z.Y. Li, Analysis of inconsistency of SIMPLElike algorithms and an entirely consistent update technique-the CUT algorithm, Numerical Heat Transfer Part B - Fundamentals 53(4) (2008) 289-312.

[38] J.H. Ferziger, M. Peric, Computational Methods for Fluid Dynamics, Springer, New York, 1996.

[39] H.L. Stone, Iterative solution of implicit approximation of multidimensional partial differential equations, SIAM Journal on Numerical Analysis 5 (3) (1968) $530-558$.

[40] T.L. Bergman, A.S. Lavine, F.P. Incropera, D.P. Dewitt, Fundamentals of Heat and Mass Transfer, seventh ed., Wiley, Hoboken, 2011.

[41] G.K. White, S.J. Collocot, Heat capacity of reference material: $\mathrm{Cu}$ and W, Journal of Physical and Chemical Reference Data 13 (4) (1984).

[42] P.D. Desai, Thermodynamic properties of iron and silicon, Journal of Physical and Chemical Reference Data 15 (3) (1986).

[43] M.J. Assael, A.E. Kalyva, K. D. Antoniadis, Reference data for the density and viscosity of liquid copper and liquid tin, Journal of Physical and Chemical Reference Data 39 (3) (2010).

[44] Y. Sato, Y. Kameda, T. Nagasawa, T. Sakamoto, S. Moriguchi, T. Yamamura, Y. Waseda, Viscosity of molten silicon and the factors affecting measurement, Journal of Crystal Growth 249 (2003) 404-415.

[45] http://www.engineeringtoolbox.com/

[46] NREL (National Solar Radiation Data Base at http://rredc.nrel.gov/solar/old_data/nsrdb/1991-2010/NCDCStationData/\#C. 


\section{Table Caption}

Table 1 . Thermophysical properties of components at $T_{m}=1076 \mathrm{~K}$.

.


Table 1 . Thermophysical properties of components at $T_{m}=1076 \mathrm{~K}$.

\begin{tabular}{|c|c|c|c|}
\hline & PCM & $\begin{array}{c}\text { HP working fluid } \\
\text { [19] }\end{array}$ & $\begin{array}{c}\text { HP wall } \\
\text { and wick } \\
{[40]}\end{array}$ \\
\hline Material & $\mathrm{Cu}-0.3 \mathrm{Si}$ & Sodium & $\begin{array}{c}\text { Stainless } \\
\text { steel }\end{array}$ \\
\hline Density, $\rho\left(\mathrm{kg} / \mathrm{m}^{3}\right)$ & $5670^{\mathrm{a}}$ & 760.2 (liquid) & 7900 \\
\hline Thermal conductivity, $k(\mathrm{~W} / \mathrm{m} \mathrm{K})$ & $300[22]$ & $\begin{array}{c}53.16 \text { (liquid) } \\
0.0482 \text { (vapor) }\end{array}$ & 19.8 \\
\hline Specific heat, $c_{p}(\mathrm{~J} / \mathrm{kg} \mathrm{K})$ & $597^{\mathrm{a}}$ & $\begin{array}{c}1267.415 \text { (liquid) } \\
265.2 \text { (vapor) }\end{array}$ & 557 \\
\hline Viscosity, $\mu$ (Pa s) & $5 \times 10^{-3 a}$ & $\begin{array}{c}2.349 \times 10^{-5} \\
\text { (vapor) }\end{array}$ & \\
\hline Latent heat, $h_{s l}$ or $h_{f g}(\mathrm{~kJ} / \mathrm{kg})$ & $721.3^{\mathrm{a}}$ & 395.1 & \\
\hline Melting point, $T_{m}(\mathrm{~K})$ & $1076[22]$ & & \\
\hline Vapor pressure, $p_{\text {sat }}(\mathrm{Pa})$ & & 4352 & \\
\hline Thermal expansion coefficient, $\beta\left(\mathrm{K}^{-1}\right)$ & $13.15 \times 10^{-6 \mathrm{a}}$ & & \\
\hline
\end{tabular}

${ }^{\mathrm{a}}$ Estimated values based on the weighted average of $\mathrm{Cu}$ and $\mathrm{Si}$ properties provided in [4145]. 


\section{Figure Captions}

Fig. 1. Physical model and computational domain for the HP and PCM.

Fig. 2. Temperature distributions of HP-PCM corresponding to Mode I (left), Mode II (middle) and Mode III (right) $\left(q_{B}=20 \mathrm{~W}, q_{T}=-20 \mathrm{~W}\right)$. (a) $L_{M}=20 \mathrm{~mm}$, (b) $L_{M}=30 \mathrm{~mm}$, (c) $L_{M}=40 \mathrm{~mm}$. Solid-liquid interfaces are shown as dashed lines.

Fig. 3. Liquid fraction histories for complete melting corresponding to $q_{B}=20 \mathrm{~W}, q_{T}=0$ and $L_{M}=40 \mathrm{~mm}$ both with and without natural convection.

Fig. 4. Solid - liquid interfaces at different times corresponding to Mode I (left), Mode II (middle) and Mode III (right) $\left(q_{B}=20 \mathrm{~W}, q_{T}=-20 \mathrm{~W}\right)$. (a) $L_{M}=20 \mathrm{~mm}$, (b) $L_{M}=30 \mathrm{~mm}$, (c) $L_{M}=40 \mathrm{~mm}$.

Fig. $5 \mathrm{HP}$ axial temperature distributions for $L_{M}=30 \mathrm{~mm}$ and $q_{B}=15 \mathrm{~W}$, (a) $q_{T}=0$ or $15 \mathrm{~W}$, (b) $q_{T}=0$ or $T_{T}=1071 \mathrm{~K}$.

Fig. 6. Liquid fraction histories for Mode I+II+III corresponding to $L_{M}=30 \mathrm{~mm}$. (a) $q_{T}=$ $-q_{B}$, (b) $T_{T}=1071 \mathrm{~K}$.

Fig. 7. HP top section output power histories for different $q_{B}\left(T_{T}=1071 \mathrm{~K}\right.$, Mode II and Mode III). (a) $L_{M}=20 \mathrm{~mm}$, (b) $L_{M}=30 \mathrm{~mm}$, (c) $L_{M}=40 \mathrm{~mm}$.

Fig. 8. Average hourly DNI during June 2010 for Albuquerque, New Mexico. (a) DNI provided by NREL [46], (b) scaled input heat transfer rate.

Fig. 9. Liquid fraction histories for Mode I+II+III corresponding to input heat transfer rate $q_{B 1}$ and $T_{T}=1074 \mathrm{~K}\left(L_{M}=20 \mathrm{~mm}\right)$. 


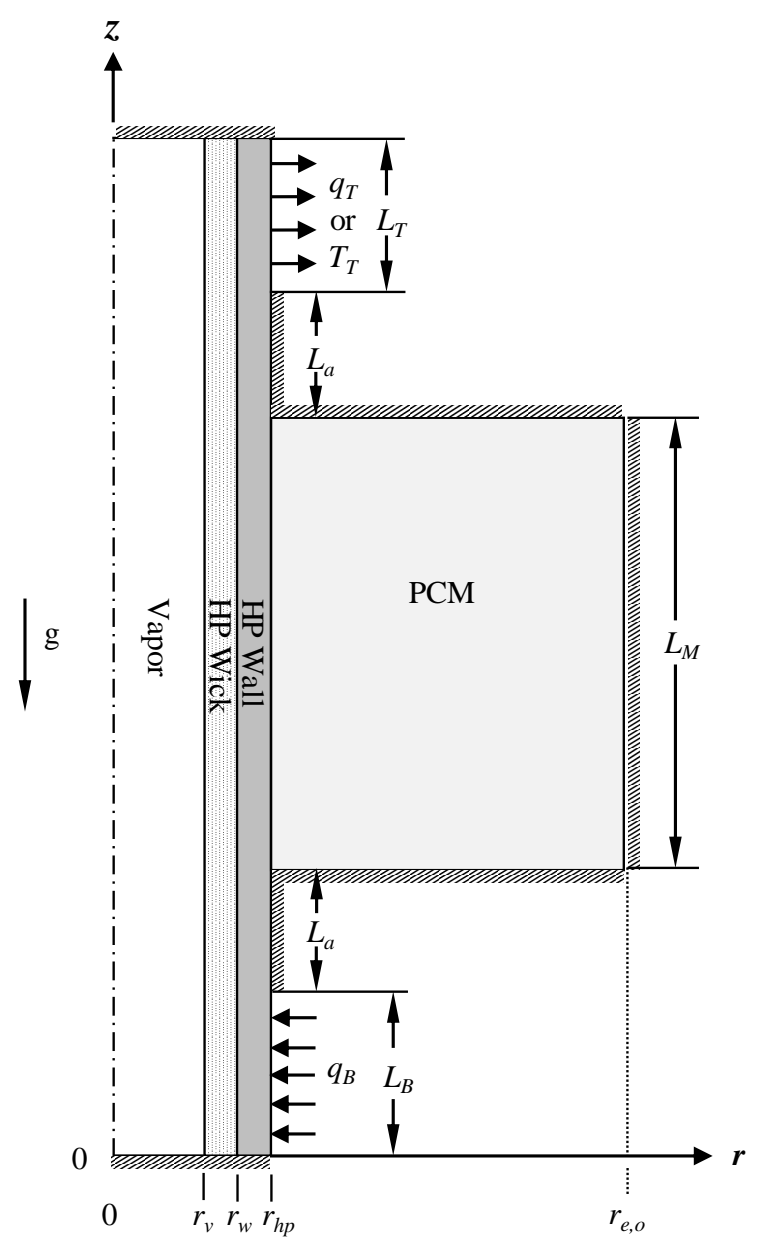

Fig. 1 Physical model and computational domain for the HP and PCM. 

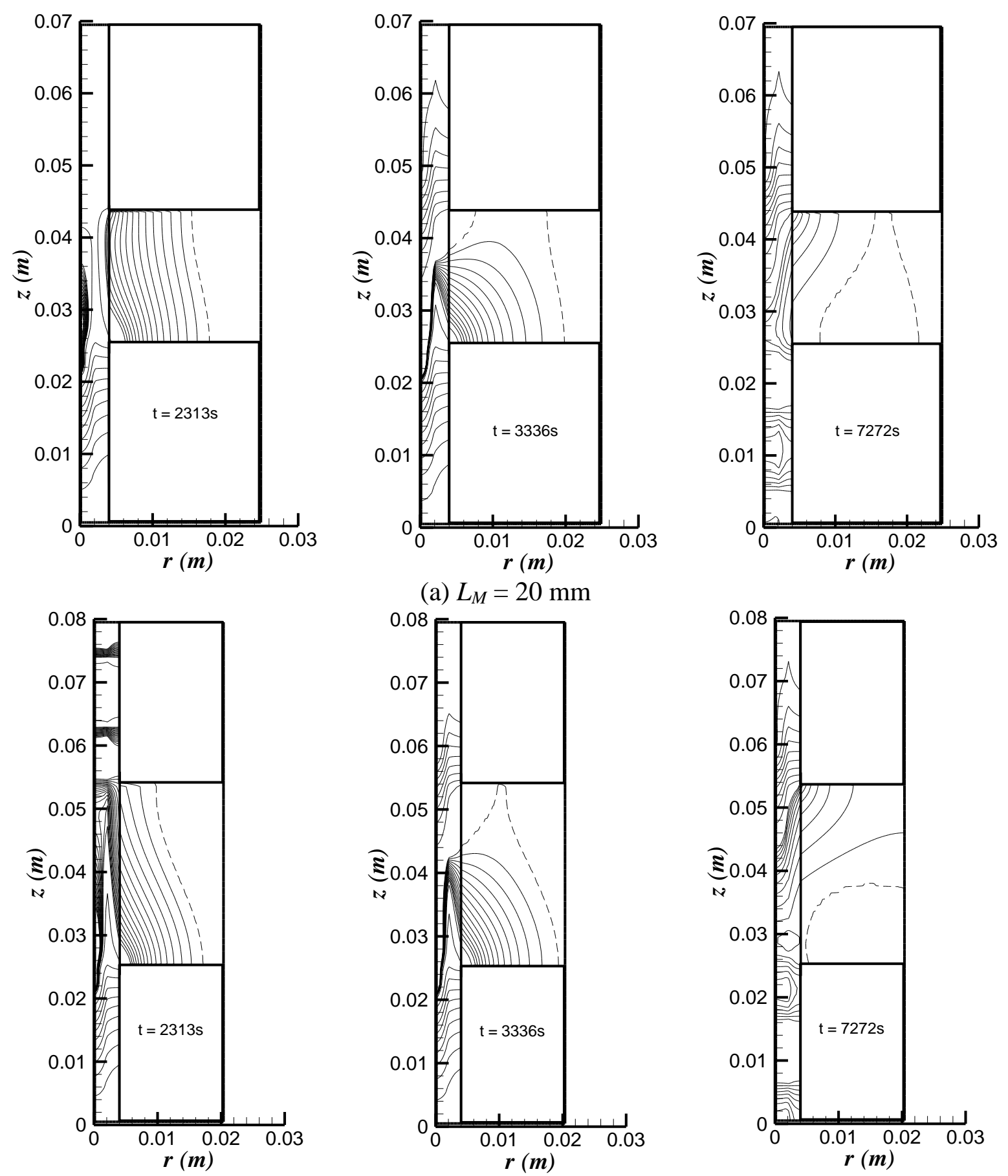

(a) $L_{M}=20 \mathrm{~mm}$
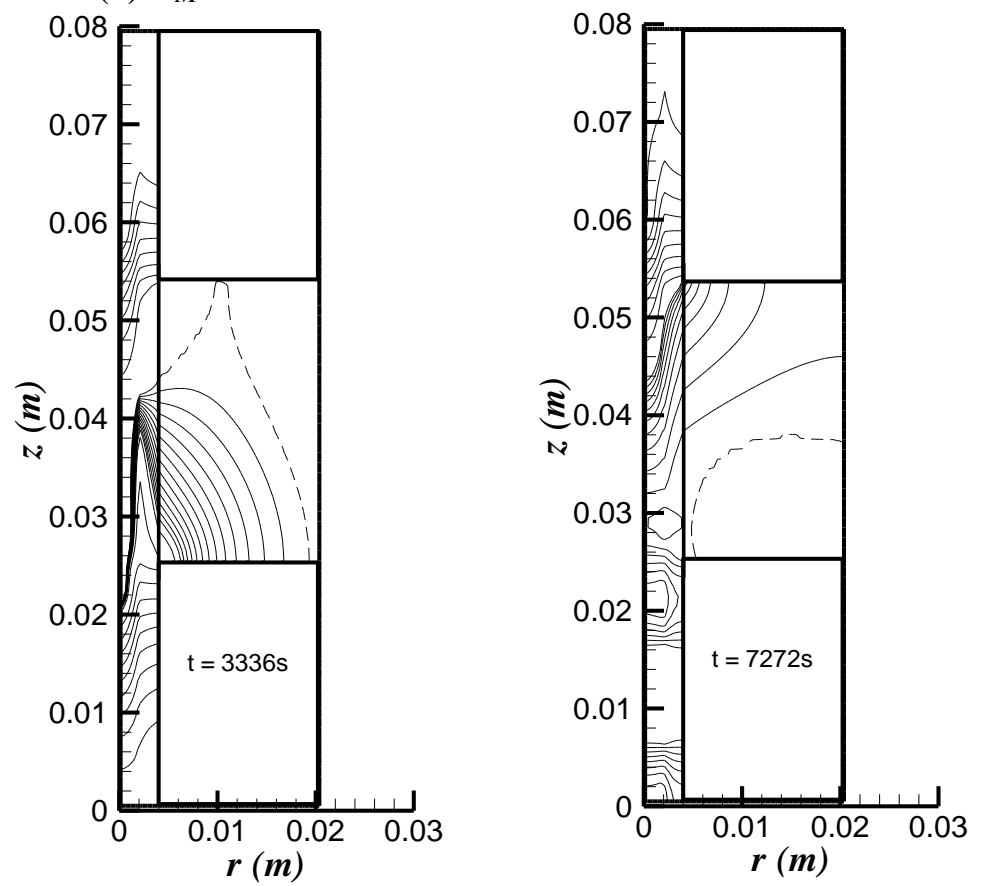

(b) $L_{M}=30 \mathrm{~mm}$ 

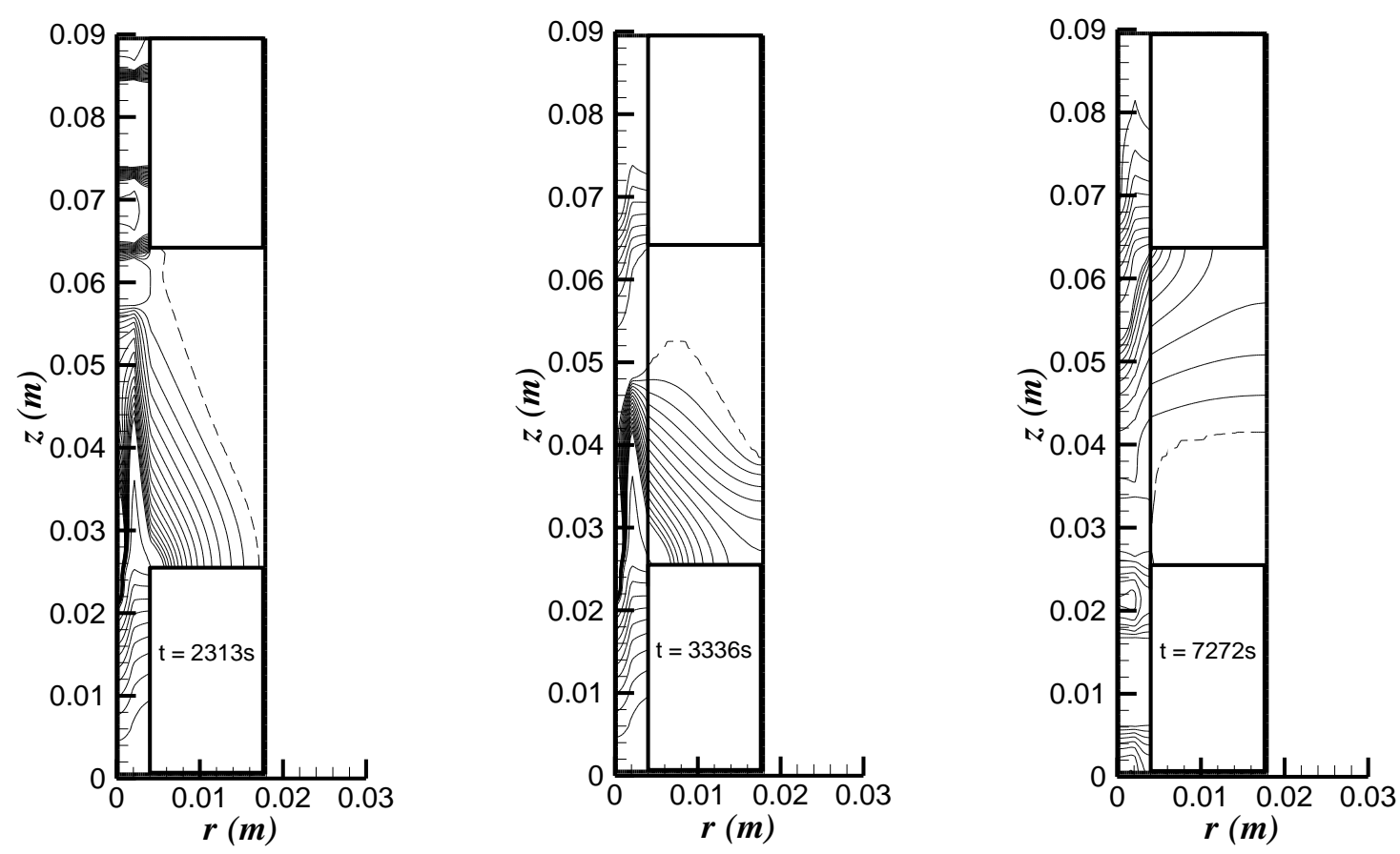

(c) $L_{M}=40 \mathrm{~mm}$

Fig. 2. Temperature distributions of HP-PCM corresponding to Mode I (left), Mode II (middle) and Mode III (right) $\left(q_{B}=20 \mathrm{~W}, q_{T}=-20 \mathrm{~W}\right.$ ). (a) $L_{M}=20 \mathrm{~mm}$, (b) $L_{M}=30 \mathrm{~mm}$, (c) $L_{M}=40 \mathrm{~mm}$. Solid-liquid interfaces are shown as dashed lines.

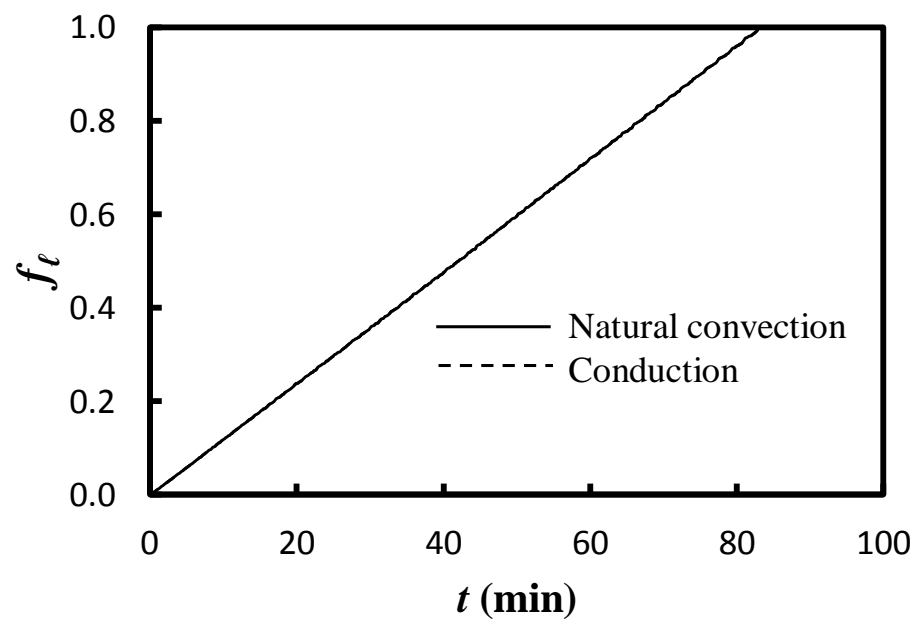

Fig. 3. Liquid fraction histories for complete melting corresponding to $q_{B}=20 \mathrm{~W}, q_{T}=0$ and $L_{M}=40 \mathrm{~mm}$ both with and without natural convection. 

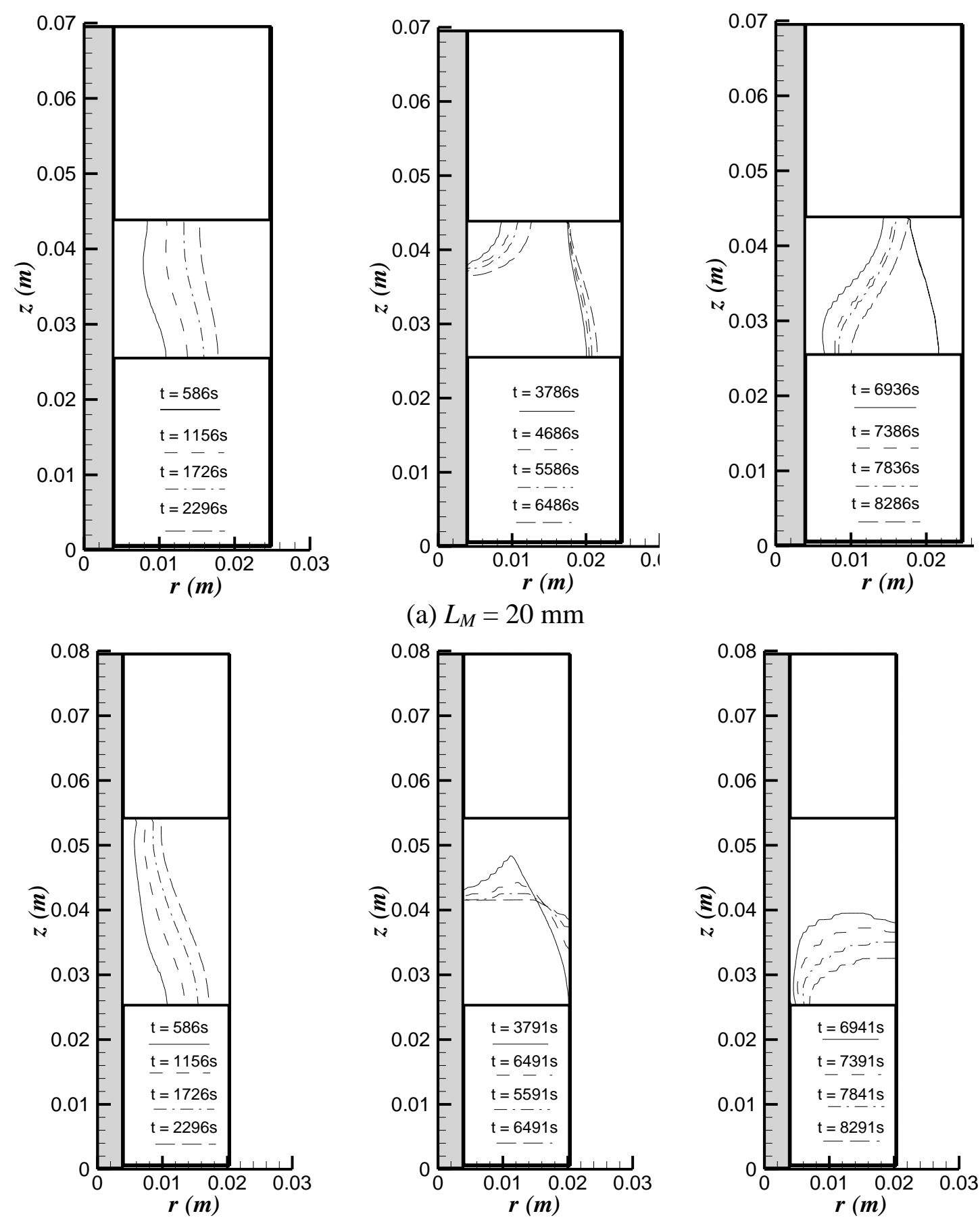

(a) $L_{M}=20 \mathrm{~mm}$
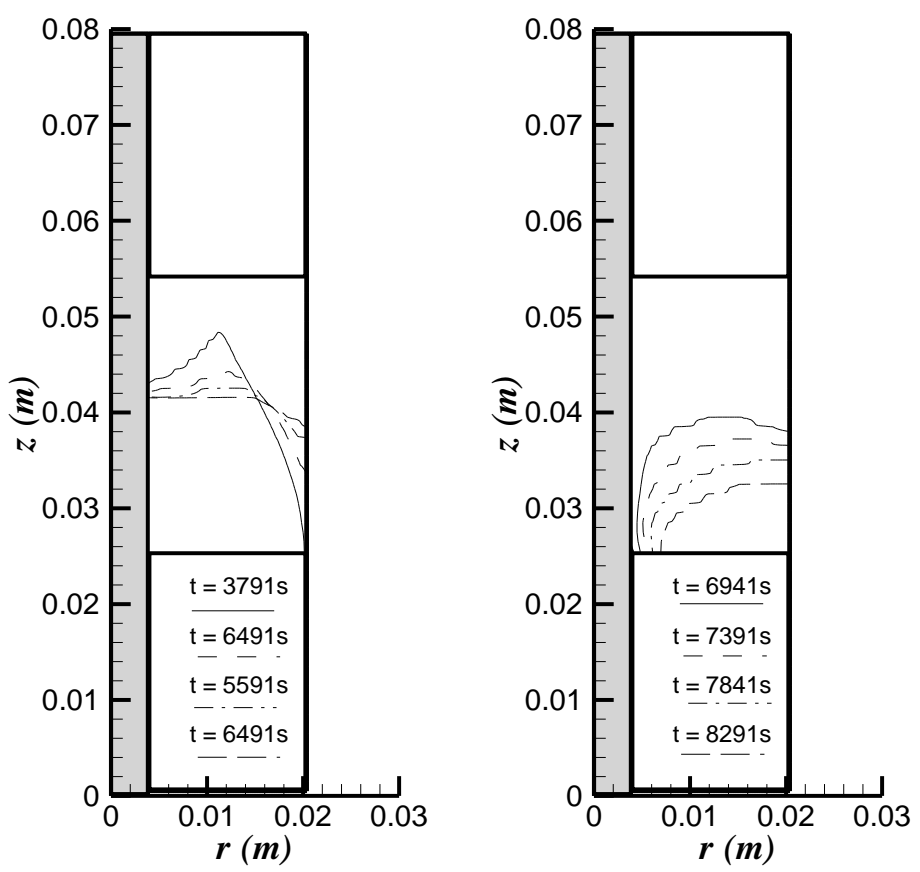

(b) $L_{M}=30 \mathrm{~mm}$ 

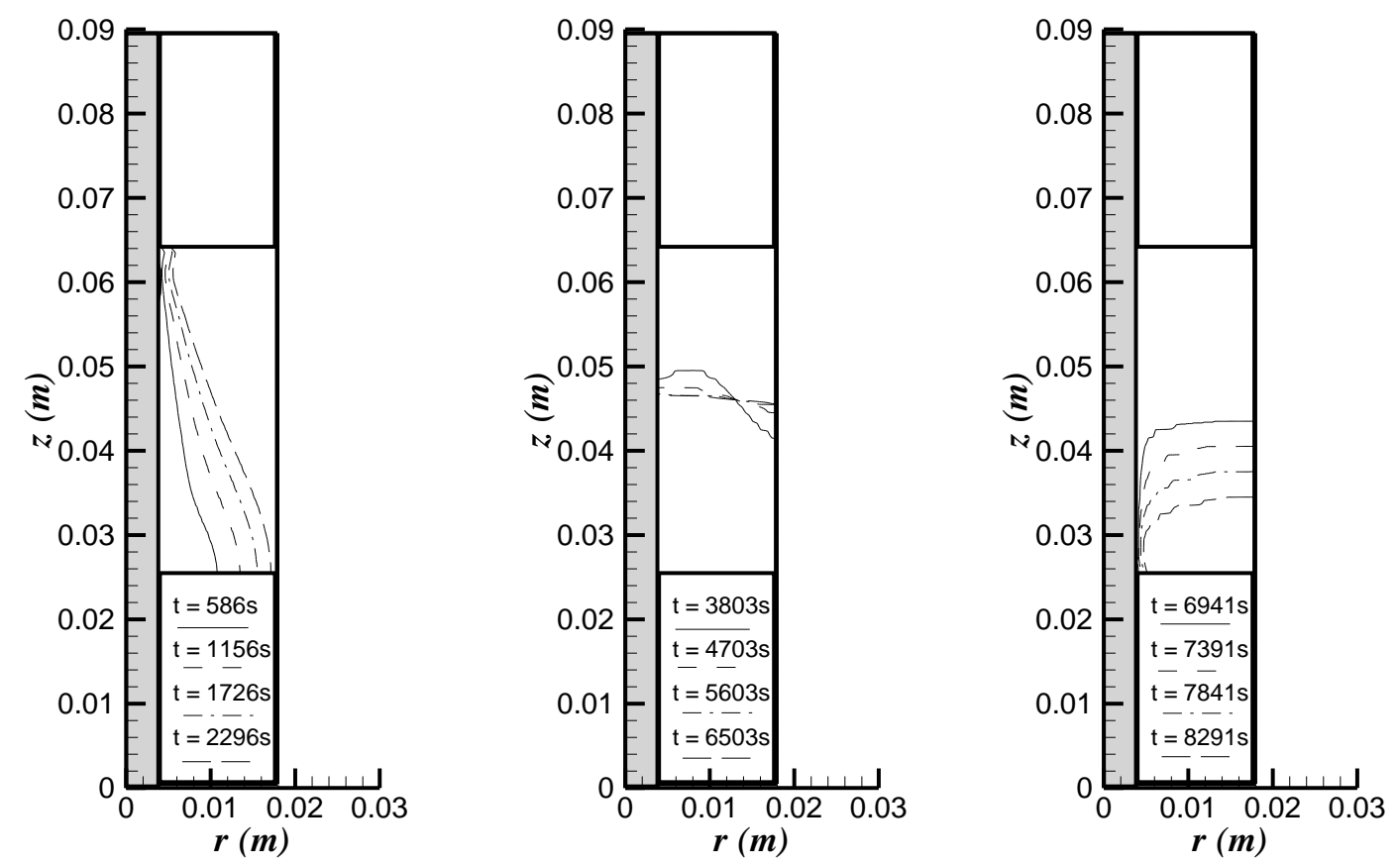

(c) $L_{M}=40 \mathrm{~mm}$

Fig. 4. Solid - liquid interfaces at different times corresponding to Mode I (left), Mode II (middle) and Mode III (right) $\left(q_{B}=20 \mathrm{~W}, q_{T}=-20 \mathrm{~W}\right)$. (a) $L_{M}=20 \mathrm{~mm}$, (b) $L_{M}=30 \mathrm{~mm}$, (c) $L_{M}=40 \mathrm{~mm}$. 


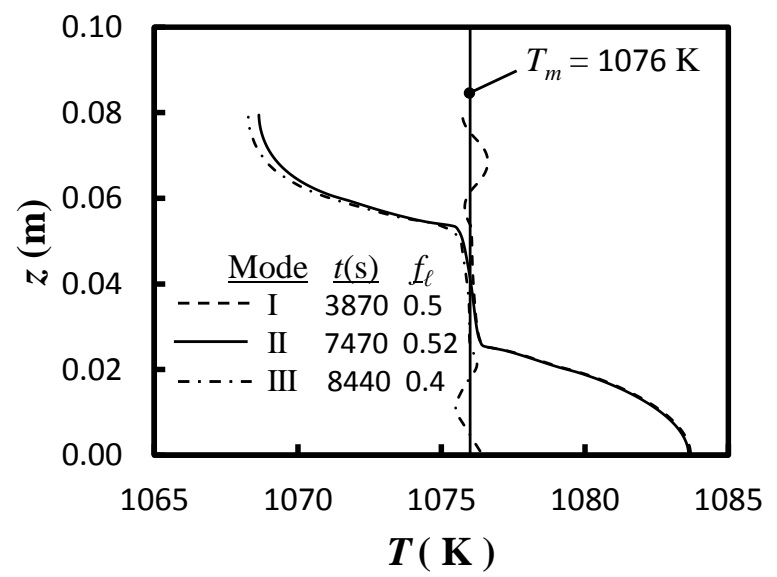

(a)

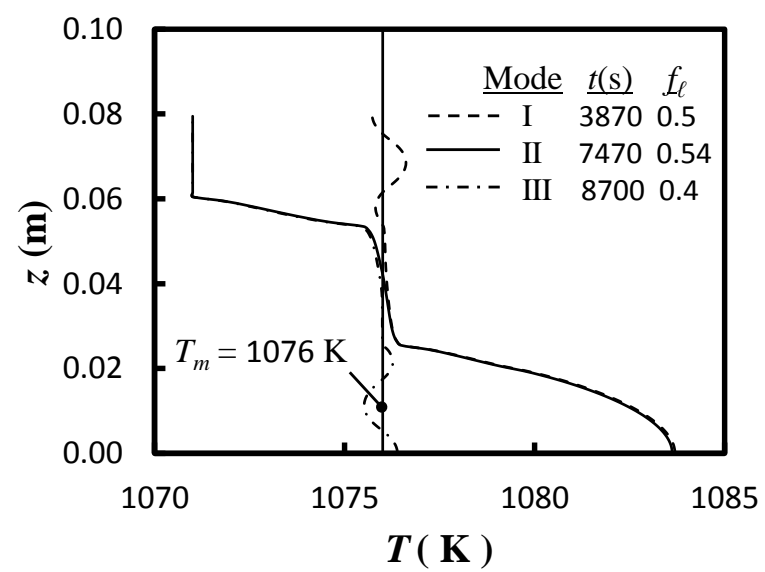

(b)

Fig. 5. HP axial temperature distributions for $L_{M}=30 \mathrm{~mm}$ and $q_{B}=15 \mathrm{~W}$, (a) $q_{T}=0$ or $15 \mathrm{~W}$, (b) $q_{T}=0$ or $T_{T}=1071 \mathrm{~K}$. 


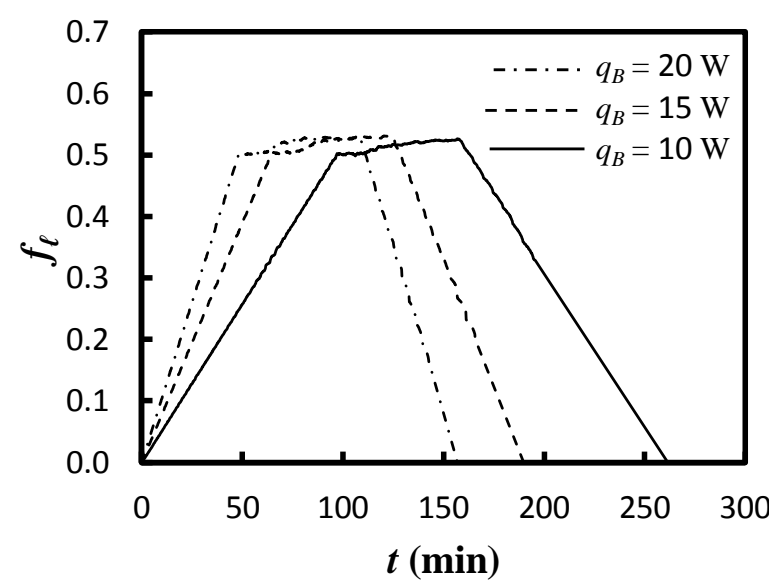

(a)

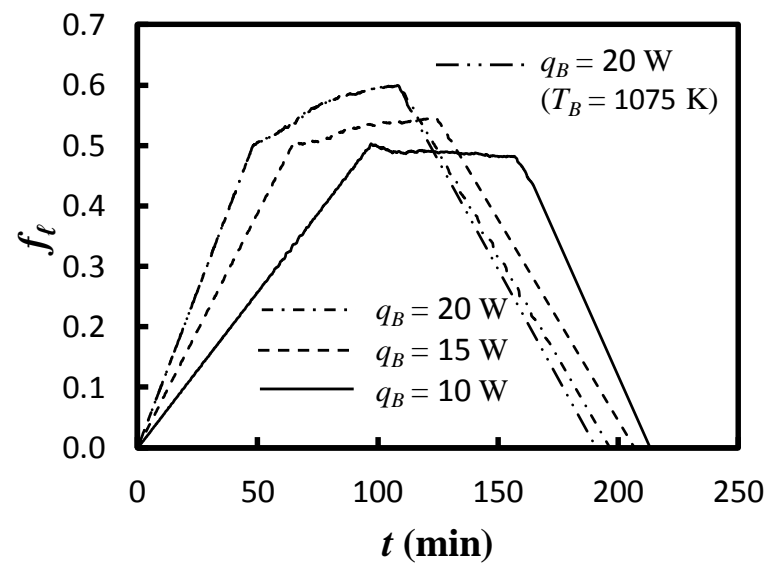

(b)

Fig. 6. Liquid fraction histories for Mode I+II+III corresponding to $L_{M}=30 \mathrm{~mm}$. (a) $q_{T}=$ $-q_{B}$, (b) $T_{T}=1071 \mathrm{~K}$. 


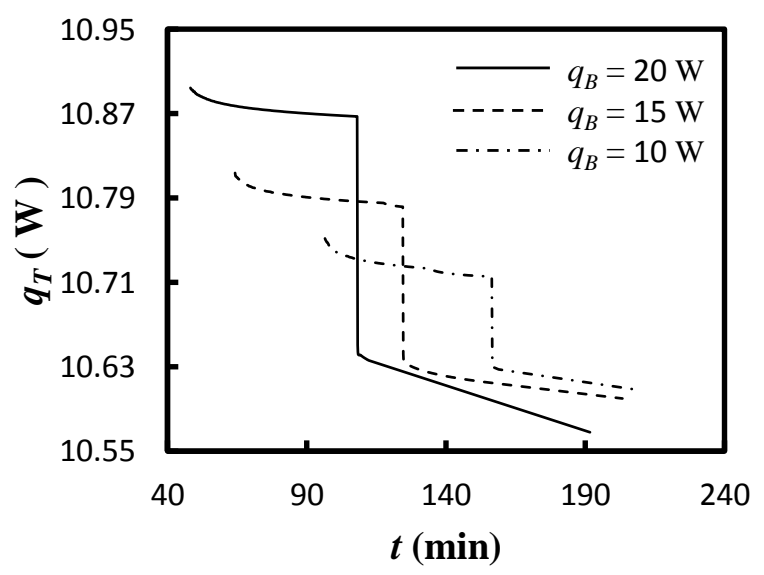

(a) $L_{M}=20 \mathrm{~mm}$

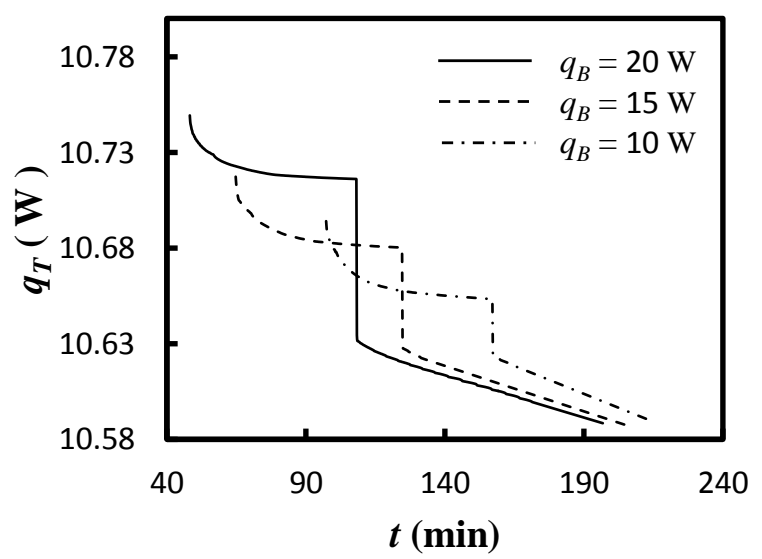

(b) $L_{M}=30 \mathrm{~mm}$

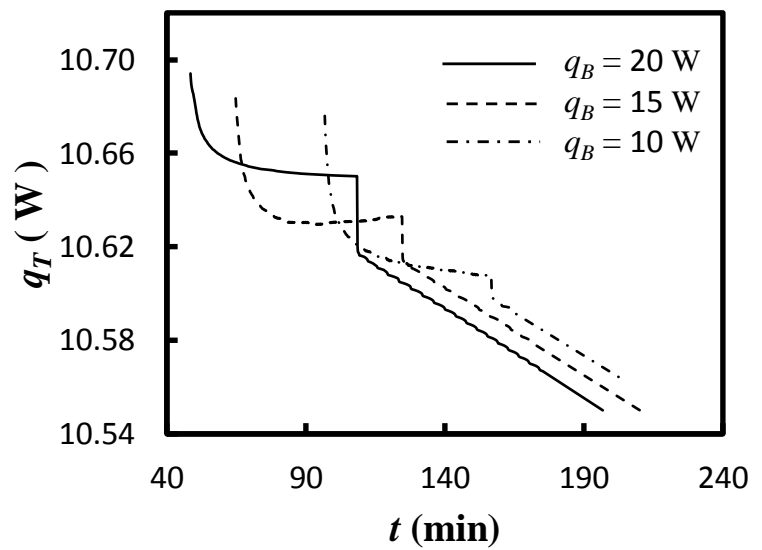

(c) $L_{M}=40 \mathrm{~mm}$

Fig. 7. HP top section output power histories for different $q_{B}\left(T_{T}=1071 \mathrm{~K}\right.$, Mode II and Mode III). (a) $L_{M}=20 \mathrm{~mm}$, (b) $L_{M}=30 \mathrm{~mm}$, (c) $L_{M}=40 \mathrm{~mm}$. 


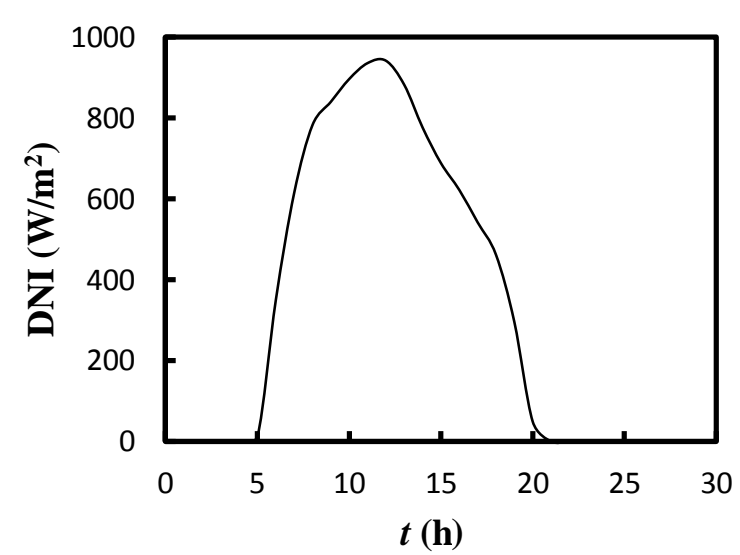

(a)

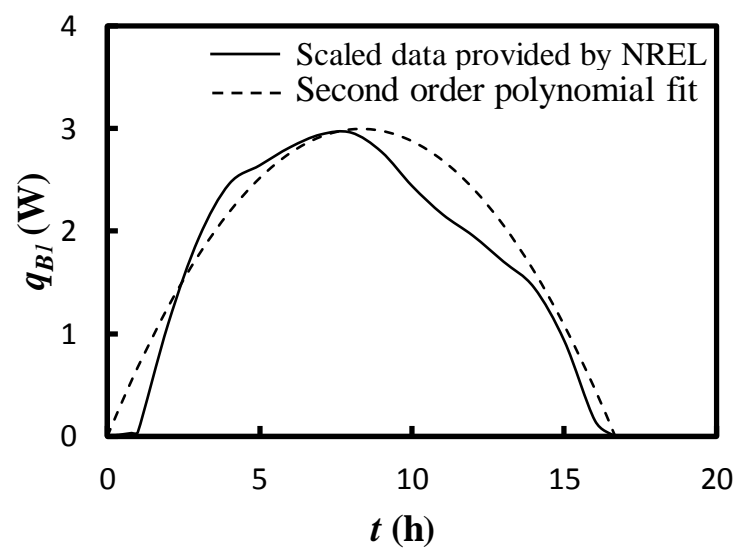

(b)

Fig. 8. Average hourly DNI during June 2010 for Albuquerque, New Mexico. (a) DNI provided by NREL [46], (b) scaled input heat transfer rate.

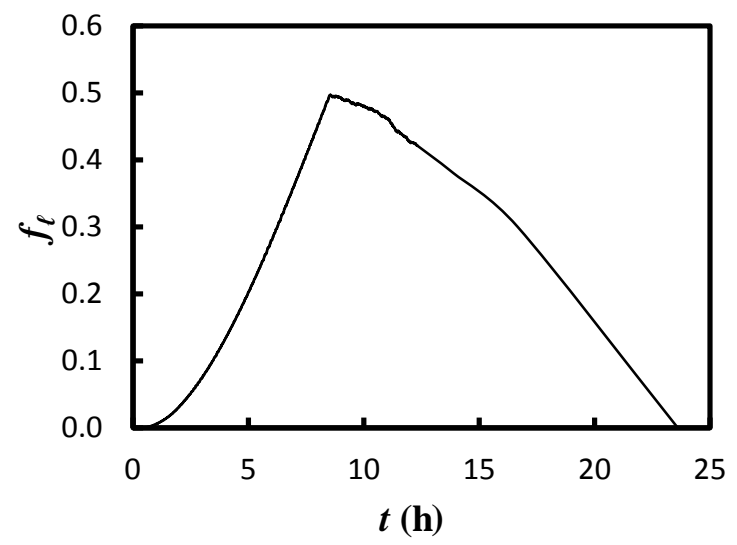

Fig. 9. Liquid fraction histories for Mode I+II+III corresponding to input heat transfer rate $q_{B 1}$ and $T_{T}=1074 \mathrm{~K}\left(L_{M}=20 \mathrm{~mm}\right)$. 